\title{
JM
}

Volume 5 No. 1 (Juli 2017)

(C) The Author(s)

\section{PERBEDAAN INTENSITAS NYERI SEBELUM DAN SESUDAH PEMBERIAN TEKNIK MASASE DAN NAFAS DALAM PADA IBU INPARTU KALA I PRIMI GRAVIDA FASE AKTIF DI RSUD DR. M. YUNUS BENGKULU TAHUN 2016}

\author{
DIFFERENCES OF INTENSITY OF PAIN BEFORE AND AFTER PROVIDING \\ MASASE AND BREATH TECHNIQUES IN MOTHER INPARTU I PRIMI GRAVIDA \\ PHASE OF ACTIVE IN DR. M. YUNUS BENGKULU YEAR 2016
}

\author{
EKASARI YP \\ AKADEMI KEBIDANAN DEHASEN BENGKULU \\ Email: EKASARIYP24@YAHOO.COM, HP: 081315500293
}

\begin{abstract}
ABSTRAK
Nyeri merupakan salah satu bagian yang dirasakan ibu inpartu kala I primi gravida fase aktif. Pemberian teknik masase dan nafas dalam dapat menjadi alternatif mengurangi nyeri persalinan inpartu kala I primi gravida fase aktif. Tujuan dari penelitian ini adalah untuk mengetahui perbedaan intensitas nyeri sebelum dan sesudah pemberian teknik masase dan nafas dalam pada ibu inpartu kala I primi gravid fase aktif. Penelitian ini mengunakan rancangan eksperimen dengan pemberian teknik masase dan nafas dalam. Populasi adalah ibu inpartu kala I primi gravida fase aktif di RSUD dr. M. Yunus Bengkulu tahun 2016. Penelitian dilaksanakan pada tanggal 03 s.d 17 Desember 2016. Sampel sebanyak 15 orang responden, pengambilan sampel secara accidental sampling. Pengumpulan data dilakukan secara observasi dan wawancara. Data dianalisa dengan menggunakan uji $t$ dengan tingkat signifikan $<0,05$. Hasil penelitian sebelum intervensi, nyeri sedang sebesar $27,0 \%$, nyeri berat sebesar $73,0 \%$ dan sesudah intervensi, nyeri sedang sebesar 53,0\%, nyeri berat sebesar 47,0\%. Hasil uji statistik mempunyai signifikasi 0,041 , dengan kesimpulan bahwa teknik masase dan nafas dalam pada ibu inpartu kala I primi gravid fase aktif efektif dalam membantu menurunkan nyeri persalinan. Bidan hendaknya melakukan teknik masase dan nafas dalam yang merupakan suatu alternative untuk menurunkan intensitas nyeri dalam satu paket tindakan pertolongan persalinan.
\end{abstract}

Kata kunci : tingkat nyeri, inpartu kala I primi gravida, masase, nafas dalam

\begin{abstract}
Pain is one of the parts perceived by the mother inpartu kala I primi gravida active phase. Provision of massage techniques and deep breath can be an alternative to reduce labor pain inpartu kala I primi gravida active phase. The purpose of this research is to know the difference of pain intensity before and after giving massage technique and deep breath to mother inpartu kala I primi gravid active phase. This research uses experimental design by giving massage technique and deep breath. The population is the mother inpartu kala I primi gravida active phase in RSUD dr. M. Yunus Bengkulu in 2016. The study was conducted on 03 until December 17, 2016. The sample was 15 respondents, sampling was accidental sampling. Data collection is done by observation and interview. Data were analyzed by using t test with significant level $<0,05$. The results before the intervention, moderate pain of $27.0 \%$, severe pain
\end{abstract}


of $73.0 \%$ and after intervention, moderate pain of $53.0 \%$, severe pain of $47.0 \%$. The statistical test results have a significance of 0.041 , with the conclusion that the massage and deep breathing technique in the inpardient mother of prime gravid phase active mother is effective in helping to reduce labor pain. Midwives should perform massage and deep breathing techniques which are an alternative to decrease the intensity of pain in a package of relief deliveries.

Keywords: level of pain, cardiac in prime gravida, massage, breath in

\section{PENDAHULUAN}

Persalinan adalah peristiwa penting yang sangat ditunggu oleh setiap pasangan suami istri dan merupakan saat yang akan sangat membahagikan setiap keluarga. Sayang sekali proses menanti kelahiran ini akan dilalui seorang ibu dengan jam-jam penuh rasa nyeri. Sebagian besar ibu yang melahirkan, merasakan nyeri persalinan dengan intensitas sangat berat sehingga menjadi sangat menderita. Nyeri saat persalinan selalu timbul akibat dari kontraksi otot rahim, yakni peregangan segmen bawah rahim dan leher rahim, membukanya mulut rahim serta peregangan otot-otot serta jaringan dasar panggul yang membentuk jalan lahir. Nyeri dirasakan sangat berat terutama oleh ibu-ibu yang baru pertama kali mengalami proses persalinan/primapara(Arfian, 2008).

Pada sebagian besar ibu-ibu nyeri persalinan merupakan suatu penderitaan, yang tidak jarang akan dirasakan untuk waktu yang cukup lama. Nyeri dalam proses persalinan bermanfaat sebagai alarm dan dapat menjadi signal buat ibu untuk mengedan (mengejan). Tetapi bila dorongan mengejan ini muncul sebelum waktunya, dapat menimbulkan efek samping berupa pembengkakan mulut rahim yang menyebabkan proses persalinan normal menjadi terganggu, bahkan akhirnya dapat terjadi persalinan harus dilaksanakan lewat tindakan operasi. Pada sebagian besar Ibu-ibu nyeri persalinan merupakan suatu penderitaan, yang tidak jarang akan dirasakan untuk waktu yang cukup lama. Selain itu nyeri juga akan menimbulkan perubahanperubahan fisiologik seperti meningkatnya tekanan darah, naiknya laju denyut jantung, menyempitnya (vasokonstriksi) pembuluh darah (arterial) dengan akibat terganggunya aliran darah ke organ-organ tubuh, meningkatnya aktifitas pernafasan, kehilangan banyak air, dan kelelahan yang sangat. Respon yang ditampilkan pasien pun berbeda - beda, secara verbal ada yang mengeluh dengan cara mengaduh, menangis, dan sesak nafas. Ekspresi wajah yang ditampakkan beragam (meringis, menggeletukkan gigi, menggigit bibir). Juga dapat terjadi perubahan-perubahan biokimia dan metabolisme tubuh. Karena derita nyeri ini, tidak jarang sebagian ibu-ibu akhirnya memilih jalan pintas mengakhiri proses persalinan lewat tindakan pembedahan (Seksio Caesaria/SC).

Tiga hal penting dan perlu diperhatikan untuk menghilangkan rasa sakit persalinan adalah keamanan, kemudahan dan jaminan terhadap homeostasis janin. Ibu bersalin yang diberikan analgesia harus dimonitor dengan baik. Menurut Arfian dalam Read (2008), intensitas nyeri persalinan berhubungan dengan tingkat emosional. Beberapa faktor yang berhubungan dengan meningkatnya intensitas nyeri persalinan dan kelahiran adalah Nuliparitas, Induksi Persalinan, Usia Ibu yang masih muda, Riwayat 'Low Back Pain' yang menyertai menstruasi dan peningkatan berat badan ibu ataupun janin.

Bidan mempunyai peran besar dalam mengurangi nyeri non farmakologi. Intervensi yang termasuk dalam pendekatan non farmakologi adalah analgesia psikologis yang dilakukan sejak awal kehamilan, relaksasi, massage, stimulasi kuteneus, aroma terapi, hipnotis, akupuntur dan yoga (Wong \& Perry, 1998).

Berdasarkan hasil study pendahuluan yang dilakukan di RSUD dr. M.Yunus Bengkulu pada bulan Oktober 2016, jumlah persalinan pada bulan Agustus 2016 sebanyak 115 persalinan, dengan rincian sebagai berikut partus normal 81 orang 
(Primipara 22 orang dan Multipara 59 orang), SC 18 orang, vakum ektraksi 7 orang dan forcep 5 orang, letsu 4 orang, dan pada bulan September 2016 sebanyak 121 persalinan, partus normal 76 orang (Primipara 25 orang dan Multipara 51 orang), SC 29 orang, vakum ektraksi 4 orang dan forcep 12 orang. Banyaknya persalinan melalui tindakan vakum ekstraksi dan forcep disebabkan karena faktor kelelahan akibat penggunaan energi dalam jumlah yang besar oleh tubuh, atau akibat penggunaan koping yang tidak tepat saat ibu merespon nyeri yang dirasakan pada saat Kala I. Dampak yang dapat terjadi akibat tindakan persalinan vakum ektraksi dan forcep dapat menimbulkan luka atau necrotis pada jaringan di luar tengkorak anak pada tempat pemasangan mangkok dan dapat menimbulkan infeksi apabila syarat asepsis dan anti sepsis kurang diindahkan sedangkan tindakan forcep dapat mengakibatkan luka pada ibu dan anak apabila tidak dilakukan dengan cara yang tepat dan benar (Wiknyosatro, 2007).

Observasi dan wawancara yang dilakukan di ruang Mawar RSUD dr. M. Yunus Bengkulu pada tanggal 5 Oktober 2016, pelaksanaan tindakan masase dan nafas dalam dilakukan bidan pada ibu bersalin belum sepenuhnya dilaksanakan untuk mengurangi nyeri persalinan. Berdasarkan masalah di atas peneliti tertarik untuk melakukan penelitian dengan judul "Perbedaan intensitas nyeri sebelum dan sesudah pemberian teknik masase dan nafas dalam pada ibu bersalin kala I di ruangan Mawar RSUD dr. M. Yunus Bengkulu tahun 2016"

\section{METODE PENELITIAN}

Penelitian ini menggunakan desain experiment, yaitu rancangan penelitian yang digunakan untuk mencari sebab akibat dengan adanya keterlibatan peneliti dalam melakukan manipulasi terhadap variable bebas (Nursalam, 2008).

\section{POPULASI DAN SAMPEL}

Populasi dalam penelitian ini adalah seluruh ibu inpartu Kala I primi gravida fase aktif (pembukaan lebih dari $4 \mathrm{~cm}$ ) yang bersalin dalam bulan Desember 2016, data persalinan pada bulan Agustus dan September 2016 sebanyak 236 persalinan, dengan jumlah ibu bersalin primi gravida fase aktif sebanyak 47 orang, yang berarti lebih kurang 24 persalinan primi gravida fase aktif per bulan.

Sampel dalam penelitian ini adalah ibu inpartu kala I primi gravida fase aktif yang bersalin di ruang Mawar RSUD dr. M.Yunus Bengkulu. Sampel diambil dengan menggunakan teknik accidental sampling dengan besar sampel 15 orang.

\section{HASIL PENELITIAN}

\section{Analisa Univariat}

Tabel 1 Data distribusi nyeri persalinan sebelum dan sesudah perlakuan masase dan nafas dalam pada ibu inpartu kala I primi gravida fase aktif di RSUD dr. M. Yunus Bengkulu tahun 2016

\begin{tabular}{ccccc}
\hline Tingkatan & \multicolumn{2}{c}{ Sebelum } & \multicolumn{2}{c}{ Sesudah } \\
\cline { 2 - 5 } Nyeri & Jumlah & $\%$ & Jumlah & $\%$ \\
\hline Sedang & 4 & 27,0 & 8 & 53,0 \\
\hline Berat & 11 & 73,0 & 7 & 47,0 \\
\hline Jumlah & 15 & 100 & 15 & 100 \\
\hline
\end{tabular}

Analisis ini dilakukan untuk memperoleh diskripsi tentang frekuensi dan prosentase intensitas nyeri persalinan pada ibu inpartu kala I primi gravida fase aktif, pada tabel $1 \mathrm{di}$ atas, nyeri sebelum pemberian perlakuan masase dan nafas dalam sebagai berikut: nyeri sedang sebesar $27,0 \%$, nyeri berat $73,0 \%$, sedangkan setelah pemberian perlakuan masase dan nafas dalam sebagai berikut: nyeri sedang sebesar $53,0 \%$, nyeri berat $47,0 \%$. 


\section{Analisa Bivariat}

Tabel 2 Mean dan standar deviasi nyeri persalinan sebelum dan sesudah pemberian teknik Masase dan Nafas dalam pemberian tehknik Masase dan nafas dalam pada ibu inpartu kala I primi gravida fase aktif di RSUD dr. M. Yunus Bengkulu tahun 2016

\begin{tabular}{cccc}
\hline & Mean & N & $\begin{array}{c}\text { Standar } \\
\text { Deviasi }\end{array}$ \\
\hline Sebelum & 0,73 & 15 & 0,458 \\
\hline Sesudah & 0,47 & 15 & 0,516 \\
\hline
\end{tabular}

Tabel 2 menujukkan mean kedua populasi. Untuk nyeri sebelum dan sesudah mendapat perlakuan masase dan nafas dalam, responden merasa nyeri rata-rata (tidak jauh berbeda) dengan selisih 0,26.

Tabel 3 Correlation dan significance nyeri persalinan sebelum dan sesudah pemberian tehknik Masase dan Nafas Dalam pada ibu inpartu kala I primi gravida fase aktif di RSUD dr. M. Yunus Bengkulu tahun 2016

\begin{tabular}{cccc}
\hline & N & Correlation & Sig. \\
\hline Sebelum-Sesudah & 15 & 0,564 & 0,029 \\
\hline
\end{tabular}

Berdasarkan tabel 3 diatas menunjukkan hasil korelasi antara kedua variable, yang menghasilkan angka 0,564 dengan nilai probabilitas di bawah 0,05 (nilai Sig.0,029).

Tabel 4 Hasil Uji $T$ Nyeri persalinan sebelum dan sesudah pemberian tehknik Masase dan nafas dalam pada ibu inpartu kala I primi gravida fase aktif di RSUD $\mathrm{dr}$. M. Yunus Bengkulu tahun 2016.

\begin{tabular}{|c|c|c|c|c|c|c|}
\hline & \multirow[t]{2}{*}{ Mean } & \multirow{2}{*}{$\begin{array}{c}\text { Std.. } \\
\text { Deviasi }\end{array}$} & \multicolumn{2}{|c|}{$\begin{array}{l}95 \% \text { CI of the } \\
\text { Defferent }\end{array}$} & \multirow{2}{*}{\multicolumn{2}{|c|}{$\begin{array}{r}\text { Sig. }(2- \\
t \quad \text { Df Tailed) }\end{array}$}} \\
\hline & & & Lower & $\overline{\text { Upper }}$ & & \\
\hline $\begin{array}{c}\text { Sebel- } \\
\text { um } \\
\text {-Sesu } \\
\text { dah }\end{array}$ & 0,267 & 0,458 & 0,13 & 0,5202 & $\begin{array}{l}2,2514 \\
6\end{array}$ & 40,041 \\
\hline
\end{tabular}

Hasil uji statistik sebagaimana tabel 4 diatas menunjukkan bahwa dengan nilai $p$ 0,041 , dimana nilai ini $<0,05$, yang berarti Ho ditolak, artinya ada perbedaan intensitas nyeri sebelum dan sesudah pemberian teknis masase nafas dalam pada ibu inpartu kala I primi gravida fase aktif.

\section{PEMBAHASAN}

Dari tabel 1 menunjukkan bahwa distribusi responden bila dihubungkan dengan tingkat nyeri persalinan pada awal atau sebelum perlakuan diketahui bahwa sebagian besar responden mengalami tingkat nyeri berat yaitu $73,0 \%$. Hal ini memperlihatkan bahwa ibu inpartu kala I primi gravida fase aktif belum memiliki pengalaman dalam mengatasi nyeri persalinan sebagaimana ibu multipara yang pernah mengalami proses persalinan sebelumnya sehingga dimungkinkan responden lebih mempersiapkan diri untuk mengurangi nyeri, Potter (1997) menyatakan bahwa seseorang telah mengalami nyeri berulang dan berhasil mengatasinya maka orang tersebut akan lebih mudah menginterpretasikan perasaan nyeri dan akan lebih baik dalam menghadapi rasa nyeri selanjutnya. Rasa nyeri persalinan primi gravida fase aktif disebabkan oleh adanya perbedaan mekanisme pembukaan serviks yaitu primi gravida fase aktif ostium uteri internum akan membuka lebih dahulu sehingga serviks akan mendatar dan menipis (Wiknjosastro, 2005), sehingga nyeri pada multipara cendrung lebih ringan dibanding dengan primi gravida fase aktif, pada penelitian ini diperoleh bahwa ada perbedaan intensitas nyeri sebelum dan sesudah perlakuan masase dan nafas dalam, hal ini sesuai dengan pendapat Mander (2003), menyatakan bahwa teknik masase dan nafas dalam dapat mengontrol nyeri persalinan.

Hasil penelitian pada tabel 2 menunjukkan ada terjadi perbedaan mean populasi, sebelum perlakuan sebesar 0,73 dan sesudah perlakuan sebesar 0,47 , hal ini memperlihatkan adanya penurunan nyeri pada ibu bersalin, sedangkan hasil uji correlation 
pada tabel 3 memperlihatkan ada sedikit perbedaan antara ke dua variabel yang menghasilkan angka 0,564 dengan nilai $p$ dibawah 0,05 (nilai Sig.0,29), hal ini menunjukkan ada hubungan antara sebelum dan sesudah pemberian teknik masase dan nafas dalam pada ibu inpartu kala I primi gravida fase aktif berhubungan secara nyata. Untuk memastikan apakah ada perbedaan secara nyata, maka dilanjutkan uji statistik (uji t berpasangan), hasilnya tertuang dalam tabel 4 bahwa ada perbedaan yang nyata pemberian teknik masase dan nafas dalam terhadap tingkat nyeri pada ibu inpartu kala I primi gravid fase aktif, sekalipun perbedaan ini tidak terlalu jauh dan ini dimungkinkan karena sampel yang terbatas, namun demikian dengan sampel yang terbatas ini menunjukkan ada pengaruh pemberian masase dan nafas dalam dapat membantu menurukan nyeri pada ibu inpartu.

\section{KESIMPULAN}

1. Ibu inpartu kala I primigravida fase aktif merasa nyeri pada tingkat berat sebesar $73,0 \%$ sebelum diberi teknik masase dan nafas dalam dan mengalami penurunan menjadi $47,0 \%$ setelah dilakukan masase dan nafas dalam.

2. Teknik masase dan nafas dalam mempunyai pengaruh bermakna dalam menurunkan tingkat nyeri inpartu kala I primi gravida fase aktif dengan signifikansi 0,041 .

3. Ada perbedaan intensitas nyeri sebelum dan sesudah pemberian teknik masase dan nafas dalam pada ibu inpartu kala I primi gravida fase aktif.

\section{SARAN}

1. RSUD dr. M.Yunus Bengkulu/lahan praktek.

a. Tenaga bidan pelaksana
Hendaknya senantiasa mengajarkan dan atau membantu ibu inpartu untuk melakukan upaya menurunkan intensitas nyeri dengan menggunakan teknik masase dan nafas dalam sebagai suatu tindakan alternative yang relative mudah dan sederhana.

\section{b. Kepala ruang VK Mawar}

Hendaknya perlu menekankan kepada para bidan pelaksana bahwa upaya membantu menurunkan intensitas nyeri pada pasien inpartu sebagai salah satu bentuk Gerakan Sayang Ibu (GSI) sehingga persalinan dipersepsikan sebagai suatu pengalaman berharga bagi perkembangan ibu.

\section{c. Peneliti lain}

Penelitian ini hendaknya dapat dilanjutkan dengan meneliti efektifitas dalam menurunkan intensitas nyeri dari beberapa teknik lainnya atau dengan jumlah sampel yang lebih banyak.

\section{DAFTAR PUSTAKA}

Andriana. E, 2007, Melahirkan Tanpa Rasa Nyerit, BIP, Jakarta

Anonim, 2002, Melahirkan tanpa rasa Sakit, www. Islam-Guide.com

Anwar, 2006, Nyeri Setelah melakukan Operasi Sesar, diakses dari www. SerbaSerbi Kesehatan.com

Arfian. A, 2008, Persalinan Tanpa Rasa Nyeri, diakses dari www. Google.com

Azwar, Saifuddin, 2014, MetodePenelitian, Pustaka Pelajar, Yogyakarta

Coffery, 2001, Faktor-faktor yang mempengaruhi nyeri, diakses dari www. Wikipedia.com

Depkes RI, 2003, Manajemen Bayi Baru Lahir untuk Dokter, Bidan dan Perawat di Rumah Sakit, (IDAI,MNH-JHPIEGO) Jakarta , 2007, Standar Profesi Bidan, Jakarta 
Henderson and Jones, 2006, Konsep Kebidanan, EGC, Jakarta

Kelly and Tracy, 2004, Teknik Relaksasi, www. Republika.com

Longulo, 2002, Persalinan Tanpa Rasa Nyeri, www. Wikipedia.com 2002, Bebas Nyeri Saat Persalinan, di akses www. Scribd.com

Mander, Rosmery, 2004, Nyeri Persalinan, EGC, Jakarta

Muhtar dan Manuaba, 1992, Nyeri Persalinan, diakses dari www. Wikipedia.com

Nursalam 2008, Riset Keperawatan, EGC, Jakarta

Parry and Potter. 2005, Fundamental Keperawatan, EGC, Jakarta.

Pengurus Pusat IBI, 2006, Buku I Standar Pelayanan Kebidanan, Jakarta , 2006, Buku II Instrumen Audit, Jakarta 2006, Buku III Catatan Tentang Perkembangan Dalam Praktek, Jakarta

Priharjo,1997, Kebutuhan Istirahat Tidur dan Kesehatan, EGC, Jakarta

Santoso, Singgih, 1999, Statistic Product and Service Solution, PT. Elex Media Komputindo, Jakarta

Suhartini, 2007, Nyeri, EGC, Jakarta

Suheimi, 2008, PersalinanTanpa Nyeri, di akses www. Scribd.com

Suririnah, 2001, Kiat Mengatasi Nyeri Persalinan, di akses www. Scribd.com

Tamsuri, 2007, Meditasi dan Relaksasi, di akses www. Kapanlagi.com

Wiknyosastro, 2007, Ilmu Kebidanan. Yayasan Bina Pustaka Sarwono Prawiroharjo, Jakarta

Wong dan Perry, 1998, Fisiologi Persalinan Normal, www. Geocities.com 